\title{
Una arqueología del paisaje argivo: sobre Sauzeau 2005
}

Cuando desde diversos horizontes se proclama de forma tan interesada como incesante la defunción del estructuralismo como metodología, a pesar de que LéviStrauss ya le dedicaba presentaciones sintéticas hace más de 50 años (Lévi-Strauss 1968: 249-309, recogiendo trabajos de 1953 y 1956), el libro de P. Sauzeau que provoca estas líneas propone una nueva aplicación que muestra de manera fehaciente cómo, más allá de las modas, el estructuralismo (los estructuralismos, en realidad, como recuerda Sauzeau) todavía permanece joven. La razón es fácil de identificar, no es otra que su capacidad de explicación, de encontrar un sentido donde previamente no lo había. Una metodología no es, no debería de ser, una cuestión de modas, es, o al menos debería de ser, una herramienta. Una herramienta sirve para determinados fines y es perfectamente inútil para otros cometidos, y en el campo de la historia de las religiones y en particular de los estudios de mitología la herramienta que es el método estructural es muy útil. Tal vez algunos lo lamenten pues esta utilidad puede tener consecuencias enojosas como, por ejemplo, (re-)introducir en la agenda la lectura de varias decenas de miles de páginas dedicadas al estudio de las religiones con esta metodología.

El libro que comentamos es, más en concreto, una aplicación específica y singularmente creativa del análisis estructural en un estudio de mitología griega entroncado en la escuela de J.-P. Vernant pero con novedades relevantes. Estas son, por una parte, la constante atención al horizonte indo-europeo, que ciertamente estaba presente en la obra de Vernant desde los años 60 (Vernant 1985: 17-106, trabajos de 1960, 1966 y 1985; 1979: 35-53, original de 1968), pero que en sus discípulos y seguidores no ha

Universidade de Santiago de Compostela. LPPP (IIT-USC), unidad asociada al IEGPS (CSIC-Xunta). e-mail phmarco@usc.es 
tenido un eco significativo (Detienne 1997, vuelve sobre Dumézil). En segundo lugar, propone el análisis de una tradición local griega de un modo que resuelve algún (pseudo)problema, como el de las relaciones entre plano local y plano panhelénico en mitología y plantea la cuestión del límite entre mito e historia en una tradición que, en definitiva, llega a nosotros como literatura. Finalmente, el argumento del libro se articula en un doble horizonte: uno temporal, pero no histórico, donde operan constantemente un plano indoeuropeo, un fondo helénico/micénico u homérico según los casos, y un análisis sincrónico de las tradiciones argivas, y otro espacial que, en mi opinión, constituye una de las mayores novedades en la medida que, fundamentalmente, consiste en explicar el sentido profundo que tiene la ubicación en lugares específicos de las tradiciones legendarias de una comarca histórica determinada. En este sentido el libro comentamos constituye "una arqueología del paisaje argivo".

Hay más cosas, como el análisis de figuras del panteón griego, con Hera y Poseidón como protagonistas, o una contribución a los estudios de género, inevitable dada la naturaleza de los mitos estudiados, o una buena serie de análisis etimológicos que conforman uno de los pilares del libro, rasgo original en su combinación con la perspectiva estructural dominante.

Comenzaré mi comentario presentando la estructura del libro, me detendré después en sus aportaciones metodológicas y terminaré dedicando un poco más de atención a un tema que me interesa de forma particular: la arqueología del paisaje, en lo que tiene de posibilidades abiertas a nuevos estudios, sea desde perspectivas estrictamente locales o de microhistoria, sea desde un punto de vista de los estudios indoeuropeos en lo que, me atrevo a sugerir, se podría llegar configurar como una topología comparada indoeuropea.

El libro se divide en cinco partes que atraviesan el argumento según una dialéctica impecable.

La primera parte, centrada en 'le nom d'Argos', plantea el problema de conjunto. Por un lado el nombre 'argos' está enormemente difundido en el mundo helénico y cuenta, además, con una clara etimología indoeuropea, con ejemplos en hitita o tocario, para referirse de forma consistente a un concepto de claras connotaciones tan positivas como difícilmente asimilables a nociones actuales, es la idea de 'blanco brillante, o luminoso, rápido y fugaz', asociada de forma nítida, además, con la noción de soberanía. Por ello el uso de ese nombre en Homero poco tiene que ver con una región concreta de Grecia y mucho con una ideología sustentadora de los valores compartidos por los helenos concentrados en sus jefes que, no por casualidad, proceden de Argos. La dialéctica entre ese horizonte panhelénico, sea el representado por Homero, por la tradición micénica o, 
incluso, por la herencia indo-europea, y las aplicaciones locales de los temas generales será constante a lo largo del libro. Por eso se presenta a Hera como la diosa específicamente portadora de los valores positivos implícitos en el uso de 'argos' como epíteto en el paisaje argivo y la descripción que hace Pausanias de ese paisaje político, en sentido estricto, como soporte de los discursos sobre los orígenes de la ciudad.

Las tres partes que siguen tratan el sistema religioso del territorio argivo apoyándose sustancialmente en el texto de Pausanias.

Al norte impera Hera (segunda parte, con el proustiano título 'Du côté de chez Héra'), en las inmediaciones de Micenas. Su santuario, el Heraion, pretende heredar además el prestigio de la antigua ciudad de forma expresa, pues el muro de sustentación de la terraza donde se levanta el templo presenta una factura pseudociclópea que imita conscientemente las prestigiosas murallas de Micenas o Tirinto. Los atributos de la estatua de culto de la diosa proporcionan el hilo conductor para conocer su definición mítico-religiosa. Se trata de una diosa polivalente, trifuncional en términos dumezilianos, básicamente soberana - con una coloración varuniana, sombría - pero con una clara dimensión guerrera y otra no menos clara dimensión fecunda y fecundante. Este último aspecto tiene, sin embargo, una dimensión inquietante de engendradora de monstruos como la Hidra de Lerna, residente en el extremo sur del territorio de la ciudad y ámbito que queda bajo el dominio de Poseidón. Esta cuestión complica, sin duda, la definición teológica de la diosa y sirve a P. Sauzeau como apoyo para su propuesta de una cuarta función que ha de agregarse a las tres definidas por Dumézil (Soberanía, Guerra, Fecundidad) para englobar genéricamente el Más Allá o el mundo Ajeno.

Tras la definición de la diosa viene el tratamiento de los mitos que tienen por base los dominios de la diosa. Primero las hijas de Preto dan pie a la intervención de Dionisio y de Ártemis al tiempo que, junto con su padre y su tío, Preto y Acrisio una de las tantas parejas de gemelos enemigos, definen el eje este-oeste del territorio argivo. En efecto, Acrisio se asienta en la acrópolis de la que va a ser la ciudad de Argos, mientras que su hermano Preto reina sobre Tirinto, sus hijas atacadas por la locura, errantes, padecen su pena y encuentran su cura hacia la frontera de Arcadia, en las montañas que limitan hacia el oeste el territorio de la polis: en el centro de este eje está Argos. El segundo es el mito de Ío, sacerdotisa del Heraion que, seducida por Zeus, suscita la terrible venganza de Hera consistente en un obligado peregrinar a través de las tres partes del mundo: Europa, Asia y África. Allí, en concreto en Egipto, dará luz a un linaje al que pertenecen, algunas generaciones después, las Danaides quienes, para escapar a un matrimonio no deseado con sus primos, huirán del país del Nilo para regresar a Argos, desembarcando en Lerna, al sur del territorio argivo, en los dominios de Poseidón y donde la propia Hera está presente a través de criaturas como la famosa Hidra derrotada por Heracles. 
Aunque Hera está presente en esta zona, el sur de Argos, sobre todo su franja costera, es el ámbito donde Poseidón manifiesta su presencia polimorfa (tercera parte: 'du côté de chez Poséidon'). Este dios no tuvo un santuario comparable al Heraion, pero en toda una serie de lugares, lagos más o menos extensos, fuentes..., distintas leyendas, ritos y sacrificios recuerdan incesantemente su presencia. Dios de las aguas y del mar sin lugar a dudas, también lo es de los abismos, de las resurgencias hídricas y, por esta vía, de unos mundos subterráneos más o menos relacionados con los ámbitos específicos de Hades. Al hilo de estos análisis se aclara la posición solo aparentemente perdedora de Poseidón en tantos mitos de ciudades griegas, pues en realidad es un dios que, a cambio de su aparente derrota domina sistemáticamente en los márgenes. Pero en este extremo sur del territorio argivo aparecen otros dioses. Sobre todo Deméter - cuya presencia puede interpretarse doblemente como pareja de Poseidón, tal como es usual en la mitología del Peloponeso, y como señora de unos misterios de Lerna, de los que se desconoce todo pero que algunos testimonios relacionan con los de Eleusis - y Dionisio, especialmente relacionado con otro mito local acerca de una suerte de bacantes procedentes del mar que pretendieron ocupar la ciudad de Argos como antecedente/paralelo de lo que será, más adelante en el tiempo mítico, el itinerario de las Danaides.

Finalmente, en el centro del eje norte-sur, Heraion-Lerna, Hera-Poseidón, y el eje este-oeste - tal vez menos destacado en el argumento del libro pero no menos presente de acuerdo con los datos presentados en los testimonios y análisis sobre las prétides - se levanta la ciudad de Argos (cuarta parte: 'La cité médiatrice'). Ciudad mediadora no solo en el plano horizontal como indican las referencias a los puntos cardinales, sino también de acuerdo con un eje vertical. En efecto, la topografía, pero sobre todo el uso religioso-mitológico de esa topografía, invitan a distinguir entre la ciudad asentada en el valle y la acrópolis (la Larissa) que la domina hacia el oeste, considerándose incluso ciertos enclaves situados a media ladera (como el teatro arcaico). Además, el examen de las fuentes y pozos que rodean la ciudad, bien reales y necesarios para el acceso al agua, subrayan si cabe la importancia de esta verticalidad que, en cierto modo, une en el enclave de la propia ciudad lo que representan el polo septentrional del Heraion, con la presencia de cultos de Hera en el ágora y a media ladera, y el polo meridional de Lerna, con diversas evocaciones en filigrana de Poseidón y el mundo subterráneo: como si el eje norte-sur se mutase, en la ciudad, en un eje arriba-abajo.

Pero los cultos de las ciudades griegas son siempre más complicados y en el corazón de la ciudad aparecen Apolo, con su epíteto Lykeios de asociaciones lobunas, y Lino, su hijo muerto por perros que se sacrifican con un rito propio de Argos, que definen el espacio de la vida humana con ayuda de metáforas pastorales bien arraigadas en el pensamiento griego. También está presente Deméter y, por supuesto, Zeus. Con 
todo, un lugar de privilegio es el ocupado por Atenea, diosa polivalente que invocada como protectora de la ciudad parece desafiar el dominio inequívoco de Hera en la polis argiva sobre el suelo del asty al tiempo que, a través de su culto, rememora las hazañas de los argivos en la epopeya.

La quinta parte, 'La légende des Danaïdes', cierra el argumento del libro y el itinerario que nos propone por los paisajes de Argos. En efecto, los ejes este-oeste, nortesur, arriba-abajo no son estáticos. Las prétides aunque proceden del este, de la Tirinto de Preto, sufren un ataque que las obliga a errar para terminar sanando en el oeste de Ártemis. Del norte, del Heraion, sale Ío y al sur, a Lerna, llegarán sus descendientes las Danaides. En el centro, Acrisio es el gemelo-enemigo de Preto. En ese mismo centro, norte y sur parecen sufrir una torsión topo-mitológica ¿habrá que decir topológica, simplemente? para devenir arriba y abajo y allí mismo irán Hipermestra y Linceo, la única pareja superviviente del matrimonio de las Danaides, para dar nacimiento al nuevo rey y a la nueva soberanía de la ciudad.

Como en cada tema tratado a lo largo dellibro, el argumento que propone P. Sauzeau es denso y todavía más cuando es preciso encontrar un hilo argumental en la masa de la bibliografía y de las teorías. En primer lugar se establece el probable origen antiguo de la leyenda, lo cual en todo caso, y justamente, no parece determinante, basándose tanto en razones etimológicas, como, de una forma particularmente esclarecedora y original, en la comparación con los mitos de la bíblica Judith y del famoso crimen de las Lemnias. Los sorprendentes paralelismos entre estas tres historias se explican por la comunidad de ideas y la facilidad de su difusión a través del Mediterráneo oriental al que pertenecen esos episodios y posibles versiones más antiguas en la literatura ugarítica e hitita - por mantener un equilibrio entre lo que es y no es indoeuropeo. En todo caso, como en cualquier buen comparativismo, las diferencias también se destacan y permiten volver, saldadas las cuentas con una parte relevante de la bibliografía, al territorio de Argos y, sobre todo, a esa última parte del bucle espacial que unirá Lerna con Argosciudad. Termina el tratamiento con una discusión del tipo de matrimonio efectuado por las Danaides y sus relaciones con otros ritos como las iniciaciones - presentes de formas diversas a lo largo del libro - o la celebración de las Tesmoforias y con el castigo de las asesinas de sus esposos la noche de bodas consistente, en definitiva, en proporcionar agua dulce del subsuelo a la llanura de Argos, del mismo modo que la hermana superviviente Hipermestra con su unión aceptada evoca el hieros gamos de Hera y Zeus en el Heraion, garantía de lluvia, y Amimone, otra hermana, acepta unirse a Poseidón, quien hace brotar una fuente de agua dulce en las cercanías de Lerna.

De esta forma, a través de los diferentes destinos de las Danaides, el esquema topológico definido por el panteón argivo se subsume en las distintas formas de acceso 
al agua necesaria para la vida humana. El mito de las Danaides actualiza el doble eje espacial que ya conocemos. Por un lado el eje norte-sur representado por Hipermestra (con Lynceo, por su nombre el lince de la montaña del oeste pero procedente de Egipto, del este, como posible evocación en filigrana del eje este-oeste, de menor peso simbólico) y Amimone; por otro el eje arriba-abajo, representado una vez más por Hipermestra que trae la lluvia, y las Danaides asesinas ambiguamente castigadas en el subsuelo de la ciudad con la misión de una hidroforía infinita hacia la superficie de la tierra. Así, el problema de la Argos 'sedienta' evocado por el epíteto homérico estudiado en la primera parte, queda resuelto y el libro llega a su fin.

Les partages d'Argos no es un libro de metodología del estudio de la religión o de la mitología. El método estructural está asumido y aceptado sin discusión, aunque ha de tenerse presente que Pierre Sauzeau, en algunas ocasiones con su hermano André, ha abordado en otros lugares cuestiones de metodología de la historia de las religiones y problemas específicos relacionados con la tradición indoeuropea (Sauzeau, Sauzeau 1995, 2000, 2002, 2004; Sauzeau 2004). Es, pues, un ejemplo más de aplicación del método de análisis estructural a un abanico de mitos griegos centrados, en este caso, en una localidad precisa. En este sentido destaca Sauzeau la diacronía y la generalización abusiva a partir de datos parciales como sendos abusos metodológicos en el estudio de las religiones evitados por el estructuralismo (Sauzeau 2005: 80, 155, 203).

También es propio del estructuralismo cierta tensión en relación con la Historia. Pero no se pretenda ver en este libro, ni en este autor, nada parecido a lo que en 1962 fue el alegato de Lévi-Strauss contra Sartre (en El Pensamiento Salvaje). El problema es otro y se relaciona, más bien, con la dimensión de profesor de literatura griega que es P. Sauzeau: se trata del estatuto epistemológico de toda una serie de textos literarios concernientes a Argos - en este caso, pero lo mismo valdría para otros lugares -, muchas veces usados por los historiadores para sus reconstrucciones del pasado, pero que Sauzeau se ha sentido legitimado para usar como integrados en la estructura mítica que explica el ser de Argos. ¿Historia o mito? Visto lo visto a lo largo del libro la prudencia aconseja proponer que la historia se construya a partir de la información arqueológica o epigráfica quedando pendiente la explicación de cómo la leyenda de Argos se ha transformado en historia, tema que formaba parte de la tesis original de Sauzeau y que él mismo se compromete a desarrollar en otros lugares (Sauzeau 2005: 337-8). Por lo demás, el mencionado sesgo profesional del autor está en línea con la poética de la mitología (presentada de forma sistemática en Calame 20oo) plasmada constantemente en el uso de los distintos textos traídos al argumento distinguiendo con cuidado sus contextos de producción, representación, público, espesor literario de las obras o pasajes citados, 
intención ideológica de los distintos autores etc. Pero llama la atención, sobre todo, la aportación de las etimologías.

Es un lugar común en los estudios de mitología inspirados por G. Dumézil una extremada precaución con el uso de las etimologías. Su propuesta se puede resumir con la idea de que, en determinados casos, la etimología de un nombre divino puede ayudar a una explicación que será, necesariamente, mitológica, basada en la manera de aparecer tal o cual personaje divino, o simplemente mítico, en una estructura compleja que lo relaciona con otros individuos de su misma especie. Lo que nunca puede hacer la etimología de un nombre es sustituir lo que dice expresamente el mito o relato donde el portador de ese nombre actúa. El caso contrario, todavía puesto en práctica por algunos indoeuropeistas hispanos, supone que el análisis lingüístico - el lingüista en realidad sustituye al mito, desconocido casi siempre en la Península Ibérica, de forma más o menos inconsciente convirtiéndose, así, en una práctica teúrgica cuya virtualidad no va más allá de la pantalla del ordenador en el que se desarrolla (Prósper 2002, comentado por González García, García Quintela 2005).

Pero Sauzeau no corre este peligro del que es bien consciente como seguidor de Dumézil (Sauzeau 2005: 81). El papel de las etimologías en Les Partages d'Argos es doble: por una parte proporcionan un fondo de antigüedad indoeuropea, pero no exclusivamente, al conjunto del análisis; por otra, las etimologías son un dato de la propia mitopoiesis helena.

En cuanto al primer aspecto, Sauzeau no establece el carácter indoeuropeo de las tradiciones que maneja únicamente por medio de comparaciones estructurales. Ciertamente, múltiples comparaciones están presentes a lo largo del libro, pero generalmente se usan para tratar temas parciales. La excepción, sustentada precisamente en la etimología de los términos pertinentes, está en la definición de los ejes espaciales que organizan el paisaje argivo que cuentan con paralelos en el mundo griego, como la oposición Argos-Pilos, Heraion-Lerna (Sauzeau 2005: 187-192) o Hera-Posidón, que además de lo dicho en este libro ha merecido un artículo específico (Sauzeau 1999). En este sentido, el diseño global del 'paisaje simbólico' de Argos (Sauzeau 2005: 58), o de su 'topología', como prefiero denominar a los mitos cuando explican de forma estructurada o coherente el sentido de ciertos paisajes, es un caso, una expresión, de una estructura heredada preexistente y compleja.

Además, las etimologías que abren el libro y reaparecen cada vez que se plantea un tema nuevo con sus protagonistas, sean estos dioses, humanos o paisajes, proporcionan constantemente un horizonte de antigüedad, no siempre indoeuropea, para los temas relatados. La etimología es, en este caso, el recurso empleado para dotar de profundidad histórica al tratamiento sincrónico dominante, propio del método estructural. Si, 
además, como ocurre en toda una serie de casos, la explicación etimológica concuerda con el sentido mitológico, se cumple de manera rigurosa el precepto metodológico de usar la etimología como medio y no como fin.

En cuanto al segundo aspecto Sauzeau recuerda que la elaboración de etimologías es un hecho heleno, estrechamente imbricado en su cultura, y aunque esas etimologías no tengan validez lingüística y parezcan inevitablemente ingenuas o superficiales a los estudiosos modernos, son una parte de la reflexión de los griegos sobre sus tradiciones. "La etimología da una perspectiva", escribe Sauzeau, "pero los significados que los Antiguos asociaban a los nombres propios no valen menos" (Sauzeau 2005: 81, y en p. 145 explica que el nombre de Ío carece de etimología científica, pero su interpretación como personificación de un grito ritual lo vincula con la conciencia lingüística de los griegos). Finalmente, el análisis etimológico tiene su lugar en el estudio de las epiclesis de los dioses, tema fundamental en cualquier análisis del panteón griego, y aquí Sauzeu propone una lección de método que merece ser citada íntegramente:

"Le problème d'une épiclèse doit être traité selon deux perspectives complémentaires, l'une panhellénique, l'autre locale: il faut réinsérer l'épithète dans la langue, dans l'ensemble de la tradition littéraire, à commencer par l'épopée... et dans l'ensemble des traditions religieuses grecques; d'autre parte, définir la fonction qu'elle occupe dans l'ensemble des représentations propres à la cité considérée" (Sauzeau 2005: 244).

Discurso de método que tiene sus raíces en la antropología de la Grecia antigua definida por J.-P. Vernant y de esta forma entramos en otra cuestión que suscita el libro. El libro procede de una tesis, y por lo tanto de un contexto académico que tiene una retórica específica que deja su huella en la publicación. No me refiero con esto a cuestiones de estilo o legibilidad del texto, impecables, sino que pretendo continuar el argumento sobre el método.

En efecto, una tesis elaborada en el marco de la antropología de la Grecia antigua difícilmente puede dar una cabida sustancial a la cuestión indoeuropea. Aunque los seguidores de esa corriente sean perfectamente conscientes del peso de la herencia indoeuropea en la cultura griega, lo cierto es que a la hora de poner en marcha sus estudios - por lo demás muy variados - tratan de captar siempre lo específico, lo propio, lo intransferible de la forma de pensar de los griegos en su manera de ver el mundo y de vivir en él. Pero de esta forma poco lugar hay para otros que no sean los mismos griegos y el horizonte indoeuropeo, en la práctica historiográfica concreta, simplemente desaparece. En este panorama es una novedad mayor el libro que comentamos con la particular combinación que propone entre perspectiva antropológica, como la revelada en el pasaje recién citado, y su aplicación a lo largo de todo el texto, y el recurso a un horizonte de referencias indoeuropeas. 
Por otra parte, también parece heredada de ese fondo académico la evocación de las iniciaciones - tan reales por la naturaleza de los mitos y ritos estudiados como inevitables en un trabajo influido por el magisterio de P. Vidal-Naquet -, o el tratamiento sobre el matrimonio haciendo eco a L. Gernet y J.-P. Vernant. Ahora bien, con estas explicaciones no pretendo deslegitimar estas aproximaciones. Al contrario. ¿Cómo entender las andanzas de jóvenes por los montes sin pensar en iniciaciones? ¿cómo pensar en historias como las de Ío o las Danaides sin relacionarlas con el matrimonio? Pretendo sugerir, más bien, que otros acercamientos podrían complementar esos análisis, al precio de proponer un texto de un volumen imposible de manejar, o sustituirlos, pero entonces el texto perdería ese referente académico, de escuela, que pretendo poner de manifiesto, nada más. Por eso queda fuera de campo, también, el tema de la cuarta función caro a P. Sauzeau: su tratamiento en el libro es ínfimo en comparación con el relieve que ha dado a esta propuesta en otros trabajos y tampoco es este el lugar para tratarlo como es debido, pero no quisiera dejarlo pasar.

La cuestión se plantea como sigue. La identificación por G. Dumézil de la ideología de las tres funciones como propia de los antiguos indoeuropeos y conservada por sus herederos históricos en una variedad de registros de la mayor importancia no cubre la totalidad de los datos de naturaleza religiosa disponibles. Esto es una realidad tan evidente como que el panteón griego difícilmente se explica dentro de este marco, aunque no así toda una serie de tradiciones locales o literarias (Sergent 1998), y en otras provincias culturales herederas de los indoeuropeos hay dioses o personajes míticos que tampoco encajan en esa estructura. Ante esta situación se adoptan tres perspectivas. La primera es negar, simplemente, la existencia de la ideología trifuncional como propia de los indoeuropeos y de sus sucesores históricos; esta opción choca en la actualidad con una ingentes masa de datos y análisis que, por el contrario, muestran su pertinencia. La segunda consiste en dejar las cosas como están: se reconoce y acepta que la ideología trifuncional no lo explica todo, pero también que hay tantos campos sin estudiar con una mirada dumeziliana que se opta por seguir acumulando estudios concretos acerca de tradiciones concretas. La tercera es buscar una solución teórica adecuada para integrar segmentos significativos de tradición heredada del fondo indoeuropeo que hasta ahora quedan fuera del marco de las tres funciones (Rees, Rees 1961, es el punto de partida).

Las propuestas sobre la cuarta función se sitúan en esta tercera línea y se muestran con dos matices diferentes. N. Allen desde una perspectiva más sociológica (téngase en cuenta que profesionalmente es un antropólogo indianista), considera que más allá de los sacerdotes, guerreros y productores (representantes de las primera, segunda y tercera funciones), la cuarta función tendría una valencia positiva, representada por el rey, y otra negativa representada por los esclavos, los shudra en el sistema de varna indio 
(Allen 1987, 1996, 1998; activamente seguido por Miller 1999, 2000, 2001, 2002). Los hermanos Sauzeau, desde una perspectiva más mitológica o cosmológica, consideran que la cuarta función integraría el mundo del Más Allá, de las potencias infernales, de los seres monstruosos. En ambos casos la cuarta función integra la alteridad en el sistema, organiza lo diferente con respecto a la norma de las tres funciones.

Es difícil fijar una posición en este debate más allá de una percepción o actitud personales. En este sentido, entiendo que mi postura depende(rá) de encontrar, o no, en mi ámbito de trabajo una(s) temática(s) concreta(s) cuyo tratamiento cuatrifuncional se imponga de forma natural ya que, a priori, no me considero comprometido en su búsqueda pues, ubicado en la segunda opción indicada más arriba, bastante trabajo me dan las estructuras trifuncionales en los ámbitos que han caído bajo mi interés. Pero también he de manifestar cierta desconfianza ante la apariencia excesivamente general de la cuarta función y que, pese a ello, sigue dejando cosas sin explicar. Sin ir más lejos, Dumézil en Loki (1986, primera edición 1948), plantea la comparación sistemática del personaje de la mitología germana que da título al libro con Syrdon, uno de los protagonistas de la epopeya caucásica, para desvelar su rol como portador de una inteligencia rápida e inmediata pero frecuentemente de enojosas consecuencias ¿Hasta qué punto sería legítimo ubicar a estos personajes en la cuarta función?

Pasemos a otra cuestión de método. P. Sauzeau propone una respuesta sensata a la falsa dicotomía, en mi opinión, entre horizonte de religión homérica, o panhelénica, y horizonte de prácticas y mitos de alcance local. Otra vez, las líneas de Sauzeau a propósito de los epítetos divinos presentan esta postura. Ambos horizontes son reales, operativos y actúan dialécticamente el uno sobre el otro con tensiones, compromisos, versiones de leyendas enfrentadas, atravesadas o no por intereses políticos, etc. En la organización del libro esta dialéctica se plantea desde el principio cuando el nombre de Argos remite primero a un horizonte indoeuropeo pero, sobre todo, cuando detecta un horizonte panhelénico en los numerosos topónimos 'Argos' y una particular presencia en la epopeya. Partiendo de estas realidades la mitología de Argos - polis del Peloponeso - no es más que una manifestación concreta, local, de ese horizonte más general del que bebe pero al que, al mismo tiempo y en la medida que es la mitología mejor conservada de ese horizonte general, alimenta o sobre el cual, incluso, ejerce su imperialismo siempre en beneficio de la tradición y prestigio de la propia Argos-polis (sirvan de ejemplo las páginas sobre los cultos de Atenea en Argos y su relación con la tradición homérica, Sauzeau 2005: 243-51).

Tal vez insistir en esto parezca una trivialidad. Sin embargo existen posturas en el ámbito de la historia de las religiones antiguas que no lo aceptan propuestas, además, por autores de prestigio. Es el caso de M. Detienne $(1997,1998)$ en su estudio "experimental" 
del politeísmo griego, consistente, hasta donde alcanzo a entender, en sugerir que más acá de las estructuras panhelénicas cada ciudad griega, cada santuario, escoge una forma particular de entender el panteón que sería impropia en cualquier otra localidad o santuario y que la idea recibida sobre tal o cual dios a través de Homero o Hesíodo puede llegar a ser muy diferente en la manera experimental que tienen los griegos de organizar el culto, o definir los poderes de los dioses, en los ambientes y contextos que consideran oportunos. Parece como si después de haber dedicado toda una parte de su obra a la elucidación del horizonte religioso panhelénico, Detienne, en esta fase de su carrera, escogiese el estudio de las tradiciones locales. Dicho de forma tal vez simplificadora en exceso, cambió a Homero por Pausanias como libro de cabecera.

Más allá de la religión griega, una postura análoga se detecta en J. Scheid, en su insistencia, inspirada por una mirada antropológica, semejante a la de J.-P. Vernant, en la especificidad de cada rito y de cada concepto manejado por los romanos, y bien está que sea así como lo demuestran sus importantes contribuciones al conocimiento de la religión romana. Pero Roma, con ser un Imperio, es también y en primer término, y sobre todo a efectos de su religión, una ciudad. Sugiero en este sentido un ejercicio de imaginación, supongamos por un momento que tenemos sobre otras ciudades o pueblos itálicos una riqueza de información religiosa de equiparable a la disponible para Roma ¿sería pertinente seguir insistiendo en lo específico de cada lugar o aparecerían rasgos comunes modulados con realidades locales? Da la impresión de que las aproximaciones que priman las lecturas locales están sesgadas por la naturaleza de la información disponible que, tratada con una metodología antropológica, o etnográfica, da como resultado estudios que recuerdan en ciertos aspectos a la erudición anticuarista.

Para la Galia prerromana la postura de J.-L. Brunaux (1996: 5-15, su título en plural contrasta expresamente con el singular propuesto por Vendryes 1997, de Vries 1963; y véanse sus respuestas a una entrevista con Ch. Goudineau, en Goudineau 2001: 273-6), es semejante cuando defiende lo específico del panteón y religión de cada ciuitas prerromana, sin aceptar que la mitología medieval del país de Gales o de Irlanda proporcione un horizonte mitológico de integración de esas manifestaciones (como proponía H. D’Arbois de Jubainville desde fines del siglo XIX). Una vez más, la mirada antropológica, o etnográfica, que prima lo específico, impide considerar series de manifestaciones religiosas a mayor escala.

Más allá del mundo antiguo lo mismo se puede decir sobre las prácticas cristianas. Si nos emplazamos en el mundo de la Reforma, el papel de lo local estaría representado por las diferentes denominaciones cargadas de particularidades teológicas y rituales, lo pertinente sería estudiar la antropología de cada denominación quedando la Biblia como materia de estudio para los semitistas y estudiosos del antiguo Israel. Si nos ubicamos 
en el mundo católico, las prácticas locales del culto a los santos o a formas particulares del culto a María, las innumerables tradiciones específicas vigentes a pesar de esfuerzos multiseculares de las autoridades eclesiásticas por domesticarlas, negarían la pertinencia de la teología vaticana y podría parecer legítimo afirmar que la Iglesia Católica no existe, siempre considerando el polimorfismo infinito de los cultos locales, que muchas veces son el resultado de series ininterrumpidas de microsincretismos, en ocasiones acumulados a lo largo de siglos.

En mi opinión, a pesar de los resultados notables conseguidos en sus trabajos por quienes mantienen estas posturas, parece como si generalizasen a partir de opciones epistemológicas o de horizontes de documentación perfectamente específicos. Si, por el contrario, optamos por otro modelo explicativo, básicamente consistente en insistir en la realidad de una dialéctica permanente entre lo general y lo particular se abren otros horizontes de comprensión de los fenómenos religiosos y Les partages d'Argos muestra que esta visión dialéctica es fructífera.

Por último me detendré en la arqueología del paisaje argivo expuesta en el libro aclarando que, desde que tuve ocasión de conocer personalmente a Pierre Sauzeau en un Coloquio celebrado en París en octubre del año 2000, pronto encontramos afinidades por la perspectiva paisajística en relación con la religión que nos interesaba a ambos. Es pertinente citar dos frases de autores completamente distintos para mostrar hasta qué punto esa convergencia de intereses se ha impuesto:

"desde el punto de vista histórico comprobamos que, aunque el paisaje cambia de forma significativa, la estructura fundamental del mismo se repite. Esta particular forma de construir el paisaje se define por la existencia de una división del espacio entre habitacional y ritual. Estos centros rituales, al encontrarse en límites o fronteras entre territorios son a la vez centro y periferia, es decir, son lugares marginales con respecto al espacio habitacional y son centro con respecto al conjunto de los territorios de las comunidades que allí limitan”. (Parcero, Santos, Criado 1998: 513, igual en Santos, Criado, Parcero 2003: 88-90; partiendo de Santos, Parcero, Criado 1997; Santos, Criado, Parcero 1998).

Por su parte Sauzeau (2005: 77) recoge y hace suyas a lo largo del libro dos sentencias de F. de Polignac en trabajos distintos pero con idéntico sentido:

"l'Héraion devenait ainsi centre et limite: centre de la constitution sociale de la cité argienne par rassemblement cultuel des groupes vivant dans le territoire; limite de l'espace où Argos se réservait la responsabilité et le droit de maintenir les règles de la civilisation agraire..." y "l'Héraion de l'Argolide constitue visiblement un meson que sa position intermédiaire plaçait au coeur des relations entre les communautés locales aussi bien qu'entre celles-ci et les régions voisines; la fonction médiatrice du culte se reflète d'abord dans sa centralité" (de Polignac 1985 : 61; 1997: 19). 
Los autores de la primera cita son arqueólogos y prehistoriadores gallegos sensibles a la identificación, como muestra la sentencia, de espacios de uso ritual definidos con una metodología que definen como 'arqueología del paisaje'. El autor de la segunda forma parte de la escuela de Vernant que desde su reconocido libro de sobre La naissance de la cité grecque (1995, primera edición de 1984) manifiesta una aguda sensibilidad hacia las formas de situarse los cultos de los dioses en el paisaje de las ciudades griegas. La raíz estructuralista es clara en los trabajos citados de F. Criado, C. Parcero y M. Santos y la misma inspiración también está presente en de Polignac. Como es sabido, una de las claves de esta metodología es la sensibilidad para con los usos humanos de la naturaleza en el más amplio sentido y, así, el paisaje y las formas posibles de su uso como orografía, como ecosistema, como topografía o geografía, como fuente de recursos para la subsistencia, es, además de todo eso, bueno para pensar en términos religiosos acerca de la forma más adecuada de relacionarse los hombres con los dioses, como lugar donde situar a los antepasados, donde emplazar necrópolis o las hazañas más o menos legendarias de los fundadores de cada comunidad (evoquemos a Lévi-Strauss 1970: 44-5, sobre la geología y su relación con el psicoanálisis).

Insistiendo en esta línea podemos recordar hasta qué punto los estudios de mitología inspirados por el estructuralismo tienen una dimensión topológica. Así, en el linaje conceptual formado por Fustel de Coulanges (1985, edición original 1864), inspirador del joven É. Durkheim (Ramos 1982: iv), fundador en su madurez de la sociología francesa donde se ubicó L. Gernet (1980: 333-51, trabajo de 1952), el maestro de Vernant (1985: 155-201, trabajo de 1963; y ver Detienne 1989: 85-98), la ubicación en el centro de la ciudad del hogar de Hestia es un dato fundamental. Por su parte M. Detienne (1983) distingue con cuidado entre los jardines de Adonis, cultivados en las azoteas de las casas de la ciudad durante la canícula, del cultivo del trigo en los campos, con su lento crecimiento presidido por Deméter. Por otro lado, la mitología de Ártemis es indisociable para P. Ellinger (1993) de la topografía de la frontera focidia. Desde un punto de vista semántico F. Hartog (1980) explica como el relato de Heródoto sobre los escitas construye una etnología, pero también una geografía de la alteridad y, desde un punto de vista sociológico, muchas páginas de P. Vidal-Naquet (1983) tratan sobre cómo jóvenes, esclavos, mujeres, artesanos... ocupan simbólicamente los márgenes de la polis griega para delimitar el lugar del ciudadano en su centro, tema al que F. Lissarrague (1990) encuentra una nueva dimensión cuando presenta la iconografía de los arqueros, peltastas y caballeros que limitan la figura, también central, del hoplita, o de las mujeres que pueblan el gineceo a veces en compañía de sátiros en los márgenes de la vida pública (Lissarrague 2003). 
En esta línea no sorprende el tratamiento que propone Sauzeau del paisaje argivo, pero también ha de decirse que en su libro la relación entre mitología y paisaje da un salto cualitativo con respecto a los antecedentes indicados en la medida que ambas dimensiones constituyen, como hemos visto, la dialéctica que estructura del trabajo. Pero ocurre, como también hemos indicado, que esa topología se presenta como única. Por una parte porque aunque se entronca con la línea general mencionada, es evidente que se trata de algo diferente; por otra porque, de acuerdo con la estrategia subyacente en el libro, no plantea una aproximación de tipo comparativo indoeuropeo en este aspecto.

Por ello me gustaría sugerir que esos elementos de comparación existen en la propia Grecia, en Roma y el Lacio y más allá y que, tal vez, sea pertinente una línea de trabajo en el ámbito de los estudios de las religiones antiguas y de la mitología que podría denominarse 'topología comparada indoeuropea' (Sauzeau 2005: 58, usa la expresión 'paisaje simbólico', sugiero que 'topología' dice lo mismo con menos letras). En lo que sigue usaré datos de un libro que preparo para colección Latomus de Bruselas con el título Le pendu et le noyé des Monts Albains. Recherches comparatives autour des mythes et rites Albains, para el que sirvieron de fuente de inspiración algunos de los trabajos de P. Sauzeau y, de esta forma, prolongar un diálogo sobre las relaciones entre paisaje y mito.

Para comenzar seguiremos en Grecia bajo el patrocinio de Hera. En Beocia, esa diosa es la protagonista del mito que justifica la celebración de las Dedalia (Pausanias IX, 2, 7-3, 1-8; Plutarco, fr. 157, 3 y 6; estudios recientes de Jost 1997, y Knoepfler 2001), fiesta que hace operativo un espacio tridimensional. En primer lugar unas groseras estatuas, las dédalas, se tallan en troncos de árboles procedentes del bosque de Alalcómenas, junto al lago Copais, en la parte más baja del territorio Beocio. Seguidamente se conducen a Platea y, en la parte final de la ceremonia, se llevan en procesión hasta la cima del monte Citerón, punto más elevado de la región en la frontera con el Ática, donde se queman en una gran pira. En torno a este eje vertical, una serie de idas y venidas implica a distintas ciudades del valle del río Asopo que articula el territorio beocio. Es relevante que Platea forma el nodo entre este plano horizontal y el eje vertical. Salta a la vista la semejanza, todo lo esquemática que se quiera, entre este paisaje y el desvelado por Sauzeau para Argos, con sus ejes norte-sur y este-oeste centrados en Argos donde, a su vez, se forma un eje vertical desde el subsuelo hasta la cima de la acrópolis. Además en ambos lugares los nombres de los accidentes naturales coinciden con los de los protagonistas de las historias que hacen relevantes las relaciones espaciales (para Laconia, Calame 1987).

Vayamos a Síbaris, en el sur de Italia. El fin de la ciudad se explica como el castigo impuesto por Hera a los sibaritas que habían asesinado a embajadores de Crotona, o a un citaredo, junto a su altar del ágora donde habían intentado encontrar asilo. Para mostrar su enojo la diosa hizo brotar un manantial inextinguible de sangre, o de bilis, 
desde el citado altar o desde su templo posiblemente en la chora, según las versiones. En otro trabajo (García Quintela 2002: 24-30) me ha parecido legítimo interpretar este episodio como la demostración de que la diosa se presenta como coextensiva, al mismo tiempo, con los asesinados que buscaban su protección, y por ello sangra y vomita bilis de un modo incontenible, como diosa inmortal que es, al contrario que los cuerpos de sus protegidos a los que la muerte privó de los flujos vitales, y con el propio territorio de la ciudad, pues el prodigio se manifiesta en el ágora y en la chora. Si pasamos a Argos, Sauzeau pone en evidencia una fusión comparable entre diosa y territorio en la medida que los cultos de la diosa están atestiguados a la vez en los polos norte y sur de la topología de la ciudad y en su centro. También aparece el tema del cuerpo desmembrado, pues los hijos de Egipto son asesinados por las Danaides en Lerna pero, decapitados, sus cabezas se entierran en Argos (Sauzeau 2005: 299-300). La relación mítica entre Hera/territorio y decapitados/territorio la establece la muerte de la Hidra de Lerna, hija de Hera en algunas versiones, que muere decapitada por Heracles, quien a su vez es constantemente objeto de la cólera de Hera y proclama con su nombre la gloria inmarcesible de la diosa (Sauzeau 2005: 176-9).

No es una novedad, ciertamente, esta relación entre cuerpo y territorio, estudiada para Roma por M. Delcourt $(1960,1963)$ en los destinos de Rómulo y de Mecio Fufecio. La diferencia entre el seguimiento de pistas o de motivos aislados y la identificación de estructuras está en que esa relación, pertinente, se enriquece si la(s) consideramos en un sistema topológico complejo.

El cuerpo de Romulo es coextensivo con el territorio de Roma en esa versión de su muerte. Pero su propia vida construye ese territorio más allá del rito de fundación (Briquel, en prensa). En efecto, uno de los ensayos que D. Briquel (1980) ha dedicado al fundador de Roma se centra en la relación que establece con tres especies arbóreas orientadas según la ideología de las tres funciones: la higuera (tercera), el cornejo (segunda) y el roble (tercera). Pero estos tres árboles se relacionan además con momentos distintos de la vida del héroe (lactancia, juventud y madurez) y con el territorio de la urbs en una doble dimensión horizontal, describiendo una suerte de circuito desde el foro, al Palatino y al Capitolio, y vertical desde el fondo del valle inundado hasta la cima dominada por Júpiter.

Por su parte Mecio Fufecio último gobernante de Alba independiente perece despedazado por su traición a Roma en un punto del valle del Tíber cerca de Fidenas y situado entre la montaña y el río tras su intento de traicionar al rey de Roma Tulo Hostilio (Tito Livio, I, 27-28; Dionisio de Halicarnaso, III, 23-30). La ubicación mediana de su suplicio entre el agua y la cumbre se pone de manifiesto si consideramos que forma sistema con el destino de Latino, el fundador del Lacio y de la dinastía que gobernará 
Alba, que sufre una apoteosis en la cima del monte Cavo (Festo, 212 L., s.v. Oscillantes), y el duodécimo representante de la dinastía de Alba, Amulio, que muere, o desaparece, en el lago Albano, en un cataclismo causado por su impiedad (Dionisio de Halicarnaso, I, 71, 3; Diodoro de Sicilia, VII, 5, 11). Esta asociación entre destinos y paisajes, cuya unidad queda marcada porque se trata de gobernantes de Alba, permite evocar los suplicios que en el Hades sufren los mayores criminales, Tito está echado en un llano que es su potro de suplicio, Tántalo es un "hundido" que muere de sed y Sísifo un "escalador" que jamás llega a la cumbre (Homero, Od., XI, 576-60o). Las semejanzas entre los personajes albanos y los delincuentes homéricos en su relación con formas del paisaje tal vez permita pensar en el reaprovechamiento de una estructura indoeuropea. Pero además, en el Lacio, aparece Júpiter en filigrana tras esos destinos humanos, pues Latino, el único personaje positivo, se convierte en el propio dios con el apelativo de Latiaris, por su parte, Amulio lo reta directamente imitando los rayos y recibe como castigo el dominio del dios sobre los meteoros y, finalmente, Mecio hace entrar en juego a Fides asociada al dios mediante la figura de Dius Fidius.

En Roma y en torno a los montes Albanos observamos, pues, la construcción de una topología tridimensional equiparable, en su indudable sencillez, a la que Sauzeau presenta para Argos.

Nos detenemos ahora en la dimensión ritual de la mano de C. Ampolo (1993) quien recuerda que sólo tres lugares reúnen la doble característica de considerarse luci y ser centros de culto de la federación latina. Contemplar estos lugares con ayuda de los análisis de Briquel sobre los árboles de Rómulo es sencillo: el lucus Nemorensis (Rasmus Brandt, Leander Touati, Zahle, 20oo) se relaciona con la realeza y la primera función, el lucus Ferentinae (Grandazzi 1996) con las reuniones del ejército lacial y la segunda función mientras que el único testimonio (Plinio, NH XVI, 91, 242) sobre el lucus de Diana de Corne presenta un rito erótico de tercera función. Hay más, pues estos tres lugares rodean el monte Cavo, el punto más alto del macizo Albano, y su santuario dedicado a Júpiter Lacial donde se celebran las Feriae Latinae en torno al cónsul romano al inicio de su mandato (Pasqualini 1996). Es decir, los tres luci orientados según las funciones definen un espacio bidimensional que gira en torno a un eje vertical presidido por Júpiter (¿un ejemplo de cuarta función, en este caso?), en una estructura paralela a la que la vida de Rómulo construye en la propia Roma.

Pero esos espacios cobran dinamismo cuando consideramos a los participantes en los ritos. En el período histórico suben al monte Cavo representantes de las ciudades de la confederación latina para sacrificar un toro blanco, hacer libaciones de queso y ofrendas de leche y terminar la ceremonia con un gran fuego en un rito de inequívoco color blanco y luminoso (Sauzeau 2005: 150, evoca rápidamente el paralelo albano). Es 
decir, las ciudades del Lacio ocupan un espacio bidimensional en torno a un eje vertical actualizado anualmente en el rito presidido, en tiempos históricos, por el cónsul romano que, con su itinerario particular, construye a su vez un espacio bipolar entre Roma y el monte Cavo.

Antes de regresar a Grecia podemos evocar el mito de Yayati (Dumézil 1971: 243-377; Defourny 1978), inserto en la epopeya india presenta otra variante de lo que parece una topología heredera del fondo indoeuropeo. Yayati, premiado por sus buenas obras, merece una apoteosis que lo lleva por los cielos junto a los dioses, pero antes de alcanzarlos tiene un pensamiento pecaminoso que le condena a caer de nuevo entre los hombres. En su descenso busca el humo de un sacrificio concelebrado por sus nietos, los hijos de su hija Madhavi con cuatro hombres diferentes - a los que no reconoce inicialmente - y que el Mahabharata presenta con coloraciones funcionales. Este eje vertical queda completado en la genealogía de Yayati con el plano horizontal definido por sus hijos, que se habían repartido previamente la soberanía de las distintas partes del territorio de la India.

No es difícil relacionar los mitos indios y los ritos romanos considerando sus dimensiones espaciales. Yayati y Latino, sendos fundadores de dinastías, sufren apoteosis que construyen un eje vertical y sagrado en torno al cual viven las comunidades que descienden de ellos. En ocasiones específicas esos hombres se reúnen portando por separado valores de las tres funciones o en los luci orientados según esas tres funciones y, sobre todo, para subrayar su relación filial con el rey-dios fundador y garante de la comunidad que define el eje vertical.

Termino. Yayati encuentra a sus nietos gracias al humo del sacrificio que asciende a los cielos. El rito del monte Albano culmina con una gran hoguera encendida en medio de la noche (Lucano, Farsalia, V, 400-403; I, 549-51). Las Dedalia de Beocia culminan con "el fuego mayor que hay, y cuyas llamas se ven desde más lejos" dice Pausanias (IX, 3, 8). Pasemos a Argos, el guardián de Ío, la vaca blanca, en el Heraion - que Apolodoro, Biblioteca II, 1, 7 identifica con un bosque sagrado alsos (= latín lucus) - es el boyero Argos Panoptes, que todo lo ve (Sauzeau 2005:138-48) y más adelante se identificará con el pavo real por su cola cubierta de miradas (Sauzeau 2005:151). Además, en la acrópolis de Argos (Larissa) había una antigua estatua de Zeus con tres ojos que P. Sauzeau relaciona con el dominio del dios sobre los tres mundos dispuestos en un eje vertical desde los cielos hasta el mundo subterráneo con el espacio bidimensional donde transcurre la vida humana en el centro (Sauzeau 2005: 258-60).

El Heraion y la Larissa comparten, vistos ahora topográficamente, unas excelentes condiciones de visibilidad sobre la llanura argiva, rasgos que reaparecen en el monte Cavo sobre el Lacio y en el Citerón sobre Beocia. Considerando todo esto tal 
vez no sea descaminado considerar los fuegos sacrificiales de Roma, la India o Beocia como equivalentes a los Zeus o Argos panópticos del mito de Argos y, a los ritos y mitos rápidamente aludidos como otras tantas variantes de una topología cuyos rasgos comunes hacen pensar en una posible herencia indoeuropea.

En definitiva, he presentado apuntes necesitados de mayor análisis pero tal vez suficientes para sugerir, al menos, la pertinencia del estudio de la topología comparada indoeuropea. Esta línea de trabajo, si llega a constituirse, tendrá uno de sus fundamentos en el libro de Pierre Sauzeau que ha servido de punto de partida a estas páginas.

La aparición del libro de Roger D. Woodard, Indo-European Sacred Space. Vedic and Roman Cult. Urbana-Chicago: University of Illinois Press, 2006, que he recensionado para Bryn Mawr Classical Review (http://ccat.sas.upenn.edu/bmcr/2007/2007-0236.html) muestra, con una temática totalmente independiente de la propuesta en el libro de P. Sauzeau y en mis propios trabajos, la vigencia y la importancia de las investigaciones comparadas que toman la mitología y el espacio como referentes.

\section{Referencias:}

Allen, N., 1987: “The Ideology of the Indo-Europeans: Dumézil’s Theory and the Idea of a Fourth Function”. International Journal of Moral and Social Studies 2, p. 23-39.

Allen, N., 1996: "Romulus and the fourth function”. En E. Polomé (ed.), Indo-european religion after Dumézil, Washington: Institute for the Study of Man, p. 13-36.

Allen, N., 1998: "Varnas, colours and functions". Zeitschrift für Religionwissenschaft 6, p. 163-77.

Ampolo, C., 1993: “Boschi sacri e culti federali: l'esempio del Lazio”. En O. De Cazanove, J. Scheid eds., Les bois sacrés, Nápoles: Centre Jean Bérard, p. 159-67.

BRIQUel, D., 1980 : “Trois études sur Romulus : B. Les trois arbres du fondateur”. En R. BLOch éd., Recherches sur les religions de l'Antiquité classique, Ginebra - París : Librairie Droz, p. 301-319.

Briquel, D. (en prensa): "L'espace consacré chez les Étrusques : réflexions sur le rituel étrusco-romain de fondation des cités”. En S. Ribichini, S. Verger, X. Dupré i Raventós, Saturnia Tellus. Roma: École Française de Rome.

Brunaux, J.-L., 1996 : Les religions gauloises. París : Errance.

CALAme, C., 1987: “Le récit généalogique spartiate: la représentation mythologique d'une organisation spatiale". Quaderni di Storia 26, p. 43-92.

Calame, C., 2000 : Poétique des Mythes dans la Grèce antique, París : Hachette.

DE Polignac, F., 1985 : “Argos entre centre et périphérie : l’espace cultuel de la société grecque”. Archives de Sciences Sociales des religions 59/1, p. 55-63.

De Polignac, F., 1995 : La naissance de la cité grecque. Cultes, espace et société, VII $-V I^{e}$ siècles, ed. revue, Paris : La Découverte.

De Polignac, F., 1997 : "Héra, le navire et la demeure : offrandes, divinité et société en Grèce archaïque”. En J. De La Genière (ed.), Héra. Images, espaces, cultes, Nápoles : Centre Jean Bérard, p. 113-22. 
DE VRies, J., 1963: La religion des celtes. París: Payot.

Defourny, M., 1978. Le mythe de Yayati dans la littérature épique et puranique. Étude de mythologie hindoue. Lieja : Université de Liège.

Delcourt, M., 1960 : "Romulus et Metius Fufetius". En Hommages à Georges Dumézil, Bruselas : Latomus, p. $77-82$.

Delcourt, M., 1963 : “Le partage du corps royal”. Studi e Materiali di Storia delle Religioni 34, p. 3-25.

Detienne, M., 1983: Los Jardines de Adonis. La Mitología Griega de los Aromas, Madrid : Akal (París 1972).

Detienne, M., 1989 : L'écriture d'Orphée, París : Gallimard.

Detienne, M., 1997 : “Expérimenter dans le champ des polythéismes”. Kernos 10, p. 57-72.

Detienne, M., 1998 : Apollon, le couteau à la main. Une approche expérimentale du polythéisme grec. París : Gallimard.

DumézIL, G., 1971 : Mythe et épopée II. Types épiques indo-européens : un héros, un sorcier, un roi, París : Gallimard.

DumézIL, G., 1986 : Loki, nouvelle édition refondue. París : Flammarion.

Ellinger, P., 1993 : La Légende Nationale Phocidienne: Artémis, les situations extrêmes et les récits de guerre d'anéantissement. Atenas : École Française de Rome.

Fustel de Coulanges, N.D., 1985: La cité antique. París: Flammarion (1864).

García Quintela, M.V., 2002: “La destrucción de Síbaris y la mitopoyesis pitagórica”. Dialogues d'histoire ancienne 28.2, p. 19-39.

Gernet, L., 1980: Antropología de la Grecia antigua. Madrid: Taurus (París 1968).

González García, F.J., García Quintela, M.V., 2005: "De la Idolatría en el Occidente Peninsular Prerromano", Ilu. Revista de Ciencias de las Religiones 10, p. 27-62.

Goudineau, CH., 2001: Le dossier Vercingétorix. Arles: Actes Sud-Errance.

GrandazzI, A., 1996 : “Identification d'une déesse : Ferentina et la ligue latine archaïque”. Comptes Rendus de l'Académie des Inscriptions, p. 273-94.

Hartog, F., 1980 : Le miroir d'Hérodote. Essai sur la représentation de l'autre. París: Gallimard.

Jost, M., 1997 : “Le thème des disputes entre Héra et Zeus en Arcadie et en Béotie”. En J. DE LA GENiÈre (ed.), Héra. Images, espaces, cultes, Nápoles : Centre Jean Bérard, p. 87-92.

Knoepfler, D., 2001 : "La fête des Daidalia de Platées chez Pausanias : une clef pour l'histoire de la Béotie Hellénistique”. En D. Knoepfler, M. Piérart, Éditer, traduire, commenter Pausanias en l'an 20oo, Ginebra, p. 343-74.

Lévi-Strauss, C., 1968: Antropología Estructural. Buenos Aires: EUDEBA (París 1958).

Lévi-Strauss, C., 1970: Tristes Trópicos. Buenos Aires: EUDEBA (París 1955).

Lissarrague, F., 1990: L'autre guerrier. Archers, peltastes, cavaliers dans l'imagerie attique. París: La Découverte.

Lissarrague, F., 2003: "Intrusiones en el gineceo". En P. Veyne, F. Lissarrague, F. Frontisi-Ducroux, Los Misterios de Gineceo, Madrid: Akal (París 1998), p. 157-198.

Miller, D.A., 1999: "Playing (with) the numbers: Variations on a Dumézilian theme". Journal of the Anthropological Society of Oxford 30, p. 35-50.

Miller, D.A., 200o: “The Second Founder and the Fourth Function: Constantine after Romulus". The Mankind Quarterly 6o, p. 327-35.

Miller, D.A., 2001: “Dumézil, Allen's fourth function, and the puzzle of the Gallo-Celtic gods”. Studia IndoEuropea 1, p. 157-69.

Miller, D.A., 2002: “Theseus and the Fourth Function”. Journal of Indo-European Studies Monographs 44, p. 95-103. 
Parcero Oubiña, C., Criado Boado, F., Santos Estévez, M., 1998: "La Arqueología de los espacios sagrados". Arqueología Espacial 19-20, p. 507-16.

Parcero Oubiña, C., Santos Estévez, M., Criado Boado, F., 1998: "Rewriting landscape: incorporating sacred landscapes into cultural traditions". World Archaeology 30, p. 159-76.

Pasqualini, A., ed, 1996: Alba Longa. Mito, Storia, Archeologia, Roma: Don Bosco.

Prósper, B.M., 2002: Lenguas y religiones prerromanas del occidente de la Península Ibérica, Salamanca: Ediciones Universidad de Salamanca.

Ramos, R., 1982: “Estudio Preliminar”. En É. Durkheim, Las Formas Elementales de la Vida Religiosa. El sistema totémico en Australia. Madrid: Akal, p. i-Xxx.

Rasmus Brandt, J., Leander Touati, A.-M., Zahle, J., eds., 20oo: Nemi-Status Quo, Recent Research at Nemi and the Sanctuary of Diana, Roma: L'Erma di Bretschneider.

Rees, A. y Rees, B., 1961: Celtic Heritage. Ancient tradition in Ireland and Wales. Londres: Thames and Hudson.

Santos Estevez, M., Criado Boado, F., Parcero Oubiña, C., 2003: "Découvertes archéologiques de sanctuaires et d'espaces sacrés”. En M.V. García Quintela et al. : Souveraineté et sanctuaires dans l'Espagne celtique. Bruselas: Mémoires de la société belge d'études celtiques, p. 75-91.

Santos Estévez, M., Parcero Oubiña, C., Criado Boado, F., 1997: “De la arqueología simbólica del paisaje a la arqueología de los paisajes sagrados". Trabajos de Prehistoria 54, p. 61-80.

Sauzeau, P. y Sauzeau, A., 1995 : "Les chevaux colorés de l'Apocalypse". Revue de l'histoire des religions 212, p. 259-98, 379-96.

Sauzeau, P. y Sauzeau, A., 2000 : La quatrième fonction. Études d'idéologie indo-européenne, Montpellier : Autor.

Sauzeau, P. y Sauzeau, A., 2002 : “Le symbolisme des métaux et le mythe des races métalliques”. Revue de l'histoire des religions 219, p. 259-97.

Sauzeau, P. y Sauzeau, A., 2004: "La quatrième fonction. Pour un élargissement du modèle dumézilien". Europe 82 no $904-905$, p. 231-53.

Sauzeau, P., 1997 : “Les quatre fonctions d'Héra”. Ollodagos 10/1, p. 131-56.

SAuzeau, P., 1998 : “L'Héritage d'Héra. Réflexions sur l'identité de la cité grecque et sur les syncrétismes antiques". En P. Million, Religiosité, religions et identités religieuses. Recherches sur la philosophie et le langage 19, p. 191-208.

Sauzeau, P., 1999: "Héra et Poséidon. Une structuration symbolique de l'espace en Grèce ancienne". Ollodagos 12/1, p. 71-110.

SAUzeau, P., 2004: "La pépinière des dieux. Sur l'ancienneté et la fonction des personnifications dans les polythéismes antiques”. En B. Pérez-Jean y P. Eichek-Lojkine (eds.), L'allégorie de l'Antiquité à la Renaissance, París : H. Champion.

Sauzeau, P., 2005 : Les Partages d’Argos. Sur les pas des Danaïdes. París: Belin.

Sergent, B., 1998 : Les trois fonctions indo-européennes en Grèce ancienne. I. De Mycènes aux tragiques. París : Economica.

Vendryes, J., 1997 : La religion des celtes. Spézet: Coop Breizh (París 1948).

Vernant, J.-P., 1979 : Religions, histoires, raisons. París : F. Maspero.

Vernant, J.-P., 1985 : Mythe et pensée chez les Grecs. Études de psychologie historique. Nouvelle éd. revue et augmentée, París : La Découverte.

Vidal-Naquet, P., 1983: El Cazador Negro. Formas de Pensamiento y Formas de Sociedad en el Mundo Griego. Barcelona: Península (París 1981). 